\title{
ESTUDO DOS CONSTITUINTES QUÍMICOS DAS CASCAS DA MADEIRA DE Trattinnickia peruviana.
}

\author{
Maria de Fátima dos Santos MARQUES ${ }^{1}$, Maria Nilce de Sousa RIBEIRO ${ }^{2}$
}

RESUMO - O estudo fitoquímico de $T$. peruviana Swart ex Loes levou ao isolamento das substâncias liquenxantona, $\alpha$ e $\beta$-amirinas, $\beta$-sitosterol, estigmasterol e campesterol, cuja identificação química foi feita através da análise de seus dados espectrais. A co-ocorrência dos esteróides é relatada pela primeira vez no gênero Trattinnickia.

Palavras-chaves: Trattinnickia peruviana; Burseraceae; Triperpenos e Esteróides.

Phytochemical Caracterization of the Stem Bark of Trattinnickia peruviana.

ABSTRACT - Phytochemical examination of a specimen of Trattinnickia peruviana Swart ex Loes led to the isolation and identification of substances lichenxanthone, $\alpha$ and $\beta$-amyrins, $\beta$ sitosterol, stigmasterol and campesterol. The identification of these natural products involved analysis of their spectral data. The occurence of three steroids is being described for the first time for genus Trattinnickia.

Key words: Trattinnickia peruviana; Burseraceae; Stem bark; Triterpenoids and Steroids.

\section{INTRODUÇÃO}

T. peruviana Swart ex Loes pertence à família Burseraceae que é constituída de espécies lenhosas e arbustivas, notáveis pelas suas secreções resiníferas, que dão particular odor na madeira,casca e galhos (LETOUZEY, 1986).

No Brasil o gênero Trattinnickia está distribuído nos Estados do Amazonas, Pará, Mato Grosso e Rondônia, onde são conhecidas popularmente como "breus".

As resinas de espécies de Burseraceae são usadas no tratamento de infecções da pele e na higiene oral (LEWIS, 1977). Na Amazônia as resinas do gênero Trattinnickia são utilizadas popularmente em ritos religiosos, defumações, perfumaria, como inseticida e na medicina popu- lar (LIMA, 1992).

Este trabalho descreve pela primeira vez a investigação fitoquímica do extrato éter de petróleo da casca da madeira de T. peruviana, envolvendo o isolamento e a identificação química das substâncias.

\section{MATERIAIS E MÉTODOS}

Um espécimen estéril de $T$. peruviana foi coletado à margem direita da estrada Manaus-Caracaraí, $\mathrm{Km} \mathrm{23}$, e foi identificado pelo botânico Dr. William Rodrigues, INPA, Manaus-Am, e registrado na Coordenação de Pesquisas em Produtos Naturais-CPPN sob o $\mathrm{N}^{\circ}$ 990/91.

As cascas da madeira $(200 \mathrm{~g})$ de $T$. peruviana, após secagem e trituração, foram extraídas com éter de

\footnotetext{
I Bolsista CNPq, RHAE/Química Fina.

2 Instituto Nacional de Pesquisas da Amazônia-INPA, Manaus-Am.
} 
petróleo à temperatura ambiente. $\mathrm{O}$ extrato foi concentrado em evaporador rotativo sob pressão reduzida, fornecendo $17,50 \mathrm{~g}$ de extrativos. Durante a concentração houve precipitação de cristais, os quais foram filtrados e recristalizados em metanol, com rendimento de $18 \mathrm{mg}$ e identificados como liquenxantona(1). Parte do extrato éter de petróleo $(7,0 \mathrm{~g})$ foi cromatografado em coluna seca de sílica gel $(0,063-0,200 \mathrm{~mm})$ desativada com 5\% de água destilada, usando como eluente clorofórmio. A coluna foi dividida em oito partes, as quais foram extraídos com diclorometano e após purificação em coluna de sílica e placa preparativa (eluente: $\mathrm{EP}+\mathrm{CH}_{2} \mathrm{Cl}_{2} \quad 1: 1$ ) permitiram $\mathrm{O}$ isolamento das substâncias: $\beta$-amirina(2), $190 \mathrm{mg} \mathrm{e}$ liquenxantona(1), $18 \mathrm{mg}$, mistura de $\alpha$ e $\beta$-amirina(2), (3), $266 \mathrm{mg}$, e mistura de $\beta$-sitosterol, estigmasterol e campesterol (4), (5), (6), $95 \mathrm{mg}$.

\section{RESULTADOS E DISCUSSÕES}

As substâncias liquenxantona(1) e $\beta$-amirina(2) foram identificadas por análise de seus dados espectrométricos (IV, RMN ' $\mathrm{H} \mathrm{e}{ }^{13} \mathrm{C}$ e EM) e pontos de fusão os quais foram comparados com valores registrados na literatura (CHAURASIA, 1987; RIBEIRO,1983; SILVA, 1989). A identificação dos componentes das misturas dos tri-terpenos (2),(3) e dos esteróides (4), (5), (6), envolveu a comparação com padrōes autênticos, utilizando CG/EM e RMN ${ }^{1.3} \mathrm{C}$ (TAMAI, 1989, SIQUEIRA, 1991).
A proporção 7:1 encontrada na mistura isomérica de (2) e (3) foi determinada por cromatografia gasosa envolvendo comparação com padrões autênticos. A mistura de $\beta$-sitosterol(4), estigmasterol(5), e campesterol(6) revelou a proporção de 4:2:1 através da análise por cromatografia gasosa.

A presença de $\alpha$ e $\beta$-amirina(2), (3) na espécie amazônica, T. peruviana, reforça mais uma vez que as espécies de Burseraceae são grandes acumuladores de triterpenos da série oleanano e ursano (KHALID,1983).

O esteróide $\beta$-sitosterol(4), é comumente encontrado em plantas superiores, porém a co-ocorrência com outros dois esteróides é relatada pela primeira vez no gênero Trattinnickia. SIQUEIRA (1992), também registrou na casca da madeira de Protium laxiflorum a ocorrência destes compostos. Esteróides são metabólitos secundários utilizados na preparação de diferentes fármacos como analgésicos, antipiréticos, antiinflamatórios e contraceptivos (ADESINA, 1983).

O largo emprego de "breus" pela população indígena e ribeirinhos da Região Amazônica para diversos fins, seja na medicina caseira( contra dor de dente e inflamações em geral), seja com outras finalidades(como inseticida e calafeto de embarcações, etc.), requer atenção especial. Um tipo de metabólito secundário individual ou como componente sinergético pode ser o responsável pela atividade biológica. A verificação da ação depende de ensaios farmacológicos das substâncias isoladas.

$\mathrm{O}$ isolamento de liquexantona 
nas cascas de T. peruviana, permitiu-nos a indagação se esta xantona seria um metabólito natural da espécie acima ou um contaminante liquênico? Xantonas de organismos inferiores são derivados biossintéticamente de acetato, obedecendo a um padrão de oxigenação meta(GEISSMAN,1969),como é o caso da liquexantona. Observações macroscópicas da casca de $T$. peruviana no manuseio para preparação do extrato, não percebemos contaminação por liquens. Para esclarecer o problema, torna-se necessária recoleta da espécie, seguida de análise microscópica do material. Após isso novo preparo de extrato e análise química do mesmo na busca de comprovação da presença ou não de liquexantona.

\section{AGRADECIMENTOS}

Os autores agradecem ao $\mathrm{CNPq}$ pela bolsa e auxílio financeiro concedidos; ao Departamento de Química da Universidade Federal de São Carlos pelos espectros de RMN ${ }^{1} \mathrm{H}$ e ${ }^{13} \mathrm{C}$ e EM da liquenxantona; ao Núcleo de Pesquisas em Produtos Naturais da Universidade Federal do Rio de Janeiro e ao Laboratório de RMN da Central Analítica do Depto de Química Orgânica e Inorgânica da Universidade Federal do Ceará pelos espectros das substâncias terpênicas e esteroidais.

\section{Literatura citada}

ADESINA, S.K.1983. Chemical examination of Khaya ivonensis and Khava senegalensis. Fitoterapia, 54: 141-143.
CABRAL,J.A.S. 1989. Biological and Chemical Evolution Cajurana.Tese de Doutoramento,University of Mississipi, USA, p80-83.

CHAURASIA, N. \& WICHTL, M. 1987. Sterols and steryl glycosides from Urtiga dioica. J. Nat. Prod. 50(5):881-888.

KHALID, S.A. 1983. Chemistry of the Burseraceae. In: Waterman,P.G. \& Grundon, M.F.(eds.) Chemistry and Chemical Taxonomy of the Rutales, London. Academic Press, p281-297.

GEISSMAN,T.A.\& CROUT,D. H.G. 1969. Organic Chemistry of Secondary Plant Metabolism.Unit States of America. Freeman, Cooper \& Company. p391-396.

LETOULEY, R. 1986. Manual of Florest Botany Tropical África. v.2b, p254-257. LEWIS, W.H. \& ELVIN-LEWIS, M.P.F. 1977. Medical Botany, Plants affeting Man's Health. Willey-Intercience, New York,347 p.

LIMA, M.P. 1992. Estudo Químico e Biológico de Tetragastris panamensis (Engl.) Kuntz (Burseraceae), Dissertação de Mestrado, Instituto Nacional de Pesquisas da Amazônia-INPA/Fundação Universidade do Amazonas-FUA, Manaus-Am, 118p.

RIBEIRO, M.N. de S. 1983. Perfil Químico do Gênero Gnetum. Tese de Doutoramento, Universidade de São Paulo-USP, São Paulo-SP, p70-74.

SIQUEIRA, J.B.G. 1991. Contribuição ao estudo fitoquimico do gênero Protium: $P$. tenuifolium (Engl.) Engl. e P. laxiflorum Engl. (Burseraceae), Dissertação de Mestrado, Instituto Nacional de Pesquisas da Amazônia-INPA/Fundação Universidade do Amazonas-FUA, Manaus-Am, $118 \mathrm{p}$.

TAMAI, M.; WATAMABE, N.; SOMEYA, M.; KONDON, H.; OMARA, S.; PEI LING, Z.; CHANG, R.; WEI MING, C. New Hepatoprotective Triterpenes from Canarium album. Planta Médica, 55: 4447.

\section{Aceito para publicação em 15.09.1994}

